\title{
Interpretation of Raman and Raman Optical Activity Spectra of a Flexible Sugar Derivative, the Gluconic Acid Anion
}

\author{
Jakub Kaminský, ${ }^{*, \dagger, \ddagger}$ Josef Kapitán, ${ }^{\dagger}$ Vladimír Baumruk, ${ }^{\S}$ Lucie Bednárová, ${ }^{\dagger}$ and Petr Bouř ${ }^{*}, \dagger$ \\ Institute of Organic Chemistry and Biochemistry, Academy of Sciences, 16610 Prague, Czech Republic, \\ Faculty of Mathematics and Physics, Charles University, Institute of Physics, Ke Karlovu 5, 12116 Prague 2, \\ Czech Republic, and Department of Chemistry of Natural Compounds, Institute of Chemical Technology, 166 \\ 28 Prague, Czech Republic
}

Received: October 17, 2008; Revised Manuscript Received: January 30, 2009

\begin{abstract}
Raman scattering and its polarized extension, Raman optical activity (ROA), are commonly used for monitoring of molecular conformational equilibria in solutions. This is complicated for saccharides due to extensive motions of the hydroxyl groups and other molecular parts. Standard interpretation procedures involving ab initio spectral simulations for a limited set of conformers are not adequate. In this study, a more general approach is proposed for the gluconic acid anion taken as a model compound, where quantum simulations of the spectra are directly coupled with molecular dynamics (MD) techniques. Such a multiscale approach reveals how the structural information is encoded in the broadened spectral lines. The spectra were simulated for solvent-solute clusters generated by MD. Conformational averaging was enabled by a limited library of conformers for which the spectral parameters could be calculated ab initio and moved on the MD geometries by Cartesian coordinate tensor transfer techniques. The B3LYP/CPCM/6-31+G** approximation was used as a default for computation of the source force fields and polarizability derivatives. The spectra thus obtained relatively faithfully reproduced most of the experimental features. The Amber and polarizable Amoeba MD force fields produced similar results; application of the latter, however, was limited by the long time necessary to achieve a converged conformational equilibrium. Both MD simulation and spectral averaging suggest that the hydroxyl groups as well as the backbone $\mathrm{C}-\mathrm{C}$ bonds rotate relatively freely, with some restrictions in the vicinity of the carboxyl group. In spite of the averaging, spectral response of characteristic vibrational normal mode families, such as $\mathrm{CH}$ and $\mathrm{OH}$ bending, can clearly be identified in the spectra. The simulations thus confirm the experimental fact that flexible saccharides exhibit significant vibrational activity that reveals precious information about molecular structure and dynamics encoded in the Raman and ROA spectral shapes.
\end{abstract}

\section{Introduction}

Since the time that measurement of Raman optical activity (ROA) was suggested ${ }^{1}$ and applied $^{2}$ for the first time, the technique has become a reliable tool for determination of absolute configurations and conformations of chiral molecules. ${ }^{3-5}$ ROA spectrum is a difference in scattering of right and left circularly polarized light, as dependent on the Raman frequency shift. ${ }^{6}$ Not only do enantiomeric species provide spectra of opposite signs, but also smaller differences in molecular structure can be amplified as changes of the ROA signal. The technique can be applied to small molecules as well as to macroscopic systems, such as viruses. ${ }^{7}$ The absolute configuration can be determined in the case of a rigid molecule ${ }^{8}$ as well as conformational equilibria. ${ }^{5,9}$ For model dipeptides, for example, we were able to reconstruct their spectra and conformer ratios from individual species with accuracy comparable to that obtained by NMR. ${ }^{10}$

For very flexible molecules, such as the gluconic acid anion (Figure 1), where most of the bonds exhibit free or semifree rotation, interpretation of the spectra from a limited number of conformers is more problematic. Yet saccharides, polysaccha-

* To whom correspondence should be addressed: e-mail kaminskj@ gmail.com (J.K.) or bour@uochb.cas.cz (P.B.).

${ }^{\dagger}$ Academy of Sciences.

* Institute of Chemical Technology.

$\S$ Charles University.

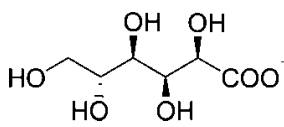

Figure 1. D-gluconic acid anion.

rides, and similar compounds provide well-defined signals with rich structural information. ${ }^{11,12}$ The importance of such molecular flexibility for a correct reproduction of Raman and ROA spectral shapes has been pointed out; for example, for the alanine zwitterion, ${ }^{13}$ where contribution of all conformers in the vicinity of the equilibrium structure could be averaged by Boltzmann weighing. Gluconic acid constitutes a much more challenging system, where systematic conformer and solvent distribution mapping goes beyond current computational possibilities. However, the extent of the computations can be reduced because of the locality and transferability of vibrational molecular properties. As is demonstrated in the present study, a combined approach where ab initio generations of the spectra are coupled with standard molecular dynamics (MD) simulations leads to qualitatively correct Raman and ROA spectral patterns. Most of the observable intensity features can thus be explained on the basis of the simulations and the spectrum related to molecular structure and dynamics.

Gluconic acid anion itself naturally occurs in metabolic cycles of most living organisms. It is also conveniently used as a pHcontrolling food additive (E574) or a chelating reagent capturing 
heavy metals. ${ }^{14,15}$ In spite of the low molecular weight, similarly as other linear saccharides, the acid anion can adopt a large number of conformations due to the flexibility of the carbon skeleton and rotations of the functional groups. We have chosen the anionic form with respect to its applications as a metal binding agent. Actual ROA monitoring of the complexation process goes beyond the scope of the present study dedicated to the free anion. Although we study a sodium salt, we do not expect any gluconate-sodium complexation because the $\mathrm{Na}^{+}$ cation, as a light element, rarely creates stable complexes with sugars. ${ }^{15}$

Whether the hydroxyl groups can stabilize preferable conformations through intramolecular hydrogen bonds remains an open question, as to our knowledge the solution structure has never been determined. In crystals an extended structure with backbone torsion angles close to $180^{\circ}$ has been found and justified theoretically, similarly as for other polyhydroxy compounds. ${ }^{16}$ However, controversial theoretical and experimental models have been proposed for the liquid phase, mostly suggesting a large conformational flexibility. ${ }^{16-21}$ Almost free rotation of the hydroxyl groups (between the three preferable staggered positions) was predicted for the glycerol molecule, which is in many aspects similar to the gluconate. ${ }^{22}$ The high degree of flexibility also best corresponds to the results presented below. Unlike for peptides and nucleic acids, a universal MD model for sugars has not yet been established. Therefore, we also find the ROA spectroscopy useful in providing feedback on the quality of the empirical force fields.

Today's applications of ROA to molecular studies are unthinkable without the possibility to simulate the spectra from the first principles. This was preceded by the first implementation allowing calculation of the ROA tensors at the Hartree-Fock level in the static approximation. ${ }^{23}$ Gauge-invariant atomic orbitals (GIAO) ${ }^{24}$ and implementations within density functional theory (DFT) $)^{25}$ made the computations more accurate. The coupled-perturbed approaches were found to be more accurate than sum-overstate formulations. ${ }^{26}$ The static approximation is usually sufficient for nonresonance spectra, although frequency dependence is available in common program packages. ${ }^{27,28}$ But the ab initio methods are very demanding of computer power. Computations of the ROA intensities are further complicated by a numerical differentiation needed to obtain the optical activity tensor derivatives, although first analytical protocols have already been suggested. ${ }^{29}$ Therefore, in this study, we explore Cartesian tensor transfer techniques ${ }^{30}$ for ROA simulations and construct molecular spectroscopic properties from a library of precalculated fragments. This enables us to average a large number of structures generated by MD with feasible computational effort.

\section{Materials and Methods}

Experimental. D-Gluconic acid and its sodium salt were purchased from Sigma-Aldrich. Both the salt solution $(\mathrm{pH}=$ 7.1 , no adjustment, $2.3 \mathrm{~mol} / \mathrm{L}$ ) and gluconate obtained from the acid (by titration with $\mathrm{NaOH}$ to $\mathrm{pH}=5.6$, at $1.4 \mathrm{M}$ final concentration) were measured. As they provided identical spectra within the noise level, only the salt results are reported. Backscattered Raman and incident circular polarization (ICP) Raman and ROA signals were recorded on the spectrometer described elsewhere. ${ }^{31,32}$ The spectra were measured at room temperature $(\sim 293 \mathrm{~K})$, with $514.5 \mathrm{~nm}$ excitation wavelength and resolution of $6.5 \mathrm{~cm}^{-1}$. Laser power at the sample was set to $440 \mathrm{~mW}$ and total accumulation time was $14.5 \mathrm{~h}$. Solvent

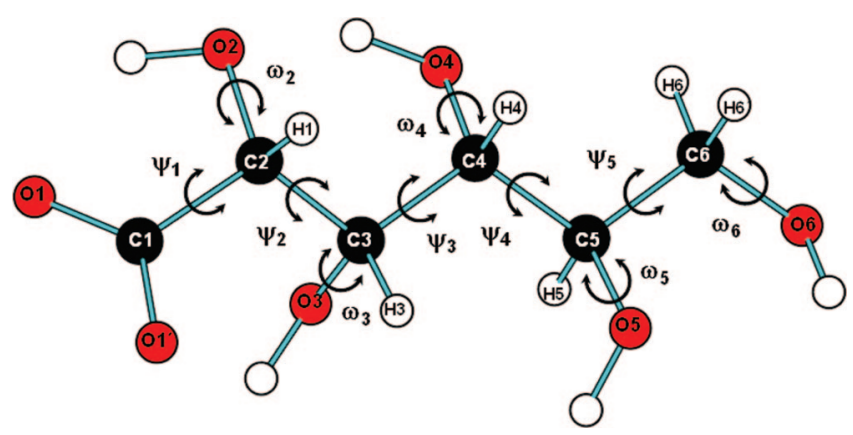

Figure 2. Definition of the torsion angles in D-gluconic acid anion: $\psi_{1}=\angle(\mathrm{O} 1-\mathrm{C} 1-\mathrm{C} 2-\mathrm{C} 3), \psi_{2}=\angle(\mathrm{C} 1-\mathrm{C} 2-\mathrm{C} 3-\mathrm{C} 4), \psi_{3}=\angle(\mathrm{C} 2-\mathrm{C} 3-$ $\mathrm{C} 4-\mathrm{C} 5), \psi_{4}=\angle(\mathrm{C} 3-\mathrm{C} 4-\mathrm{C} 5-\mathrm{C} 6), \psi_{5}=\angle(\mathrm{C} 4-\mathrm{C} 5-\mathrm{C} 6-\mathrm{O} 6), \omega_{2}$ $=\angle(\mathrm{C} 1-\mathrm{C} 2-\mathrm{O} 2-\mathrm{H}), \omega_{3}=\angle(\mathrm{C} 2-\mathrm{C} 3-\mathrm{O} 3-\mathrm{H}), \omega_{4}=\angle(\mathrm{C} 3-\mathrm{C} 4-$ $\mathrm{O} 4-\mathrm{H}), \omega_{5}=\angle(\mathrm{C} 4-\mathrm{C} 5-\mathrm{O} 5-\mathrm{H}), \omega_{6}=\angle(\mathrm{C} 5-\mathrm{C} 6-\mathrm{O} 6-\mathrm{H})$.

$\left(\mathrm{H}_{2} \mathrm{O}\right)$ part was subtracted from the Raman signal and a minor baseline correction was made for both Raman and ROA spectra.

Molecular Dynamics. MD simulations were performed with the Tinker program ${ }^{33}$ using the Amber95, ${ }^{34}$ Amber99, ${ }^{35}$ and Amoeba $^{36}$ force fields. The Amber fields model electrostatic interactions with static atomic partial charges and use the TIP3P ${ }^{37}$ water model, while Amoeba additionally accounts for polarization effects and uses its own water parameters. Partial atomic charges in the $\mathrm{COO}^{-}$group undefined in Amber95 were set to $q_{\mathrm{C}}=0.8$ and $q_{\mathrm{O}}=-0.9$ (predefined Amber99 values are $q_{\mathrm{C}}=0.8831$ and $q_{\mathrm{O}}=-0.8055$ ). D-Gluconic acid (Figure 1) was placed in a cubic water box $18.7 \AA$ wide with periodic boundary conditions; after minimization and equilibration stage ( $\sim 10 \mathrm{ps}$ ), the system was allowed to evolve $1 \mathrm{~ns}$ with $1 \mathrm{fs}$ integration time steps as an $\mathrm{NpT}$ ensemble, at pressure $1 \mathrm{~atm}$ and temperature $298 \mathrm{~K}$. MD geometries were recorded at $1 \mathrm{ps}$ intervals, providing in total 1000 structures. For the Amber95/ 99 force fields a longer 75 ns run could additionally be set up, providing 7500 structures at 10 ps sampling.

Ab Initio Computations. D-Gluconic acid anion comprises 10 torsion angles (Figure 2) and a complete conformational space mapping with accurate ab initio methods is currently not feasible. For example, a rough scan with $120^{\circ}$ steps would provide $3^{10}=59409$ conformers. Note that the CPU time needed for generation of one conformer ROA spectrum at the level given below is about 1 month (AMD $642-\mathrm{GHz}$ processor). Therefore, we created a limited library of conformers only. For a starting extended structure $\left(\psi_{1-5} \sim 180^{\circ}\right)$ obtained randomly from $\mathrm{MD}$, we varied the five $\mathrm{OH}$ angles $\omega_{2}-\omega_{6}$ independently one by one, which provided the starting structure, structure with $\omega_{2}$ increased by $120^{\circ}$, structure with $\omega_{2}$ increased by $240^{\circ}$, structure with $\omega_{3}$ increased by $120^{\circ}$, etc. This set of $5 \times 3=$ 15 geometries was subjected to energy minimization at the B3LYP ${ }^{38} / 6-31+\mathrm{G}^{* *} / \mathrm{CPCM}$ approximation level performed with the Gaussian ${ }^{27}$ program. The library was complemented by 12 geometries obtained from MD comprising also bended structures where the backbone angles $\psi_{1-5}$ significantly deviated from $180^{\circ}$, so that also each backbone angle for $\psi_{i} \sim 60^{\circ},-60^{\circ}$, and $180^{\circ}$ occurred at least once in the library. The MD geometries were subjected to a constrained normal-mode optimization $^{39,40}$ that allowed the high-energetic vibrations to relax, while the MD geometries were almost unaffected. Modes between -300 and $300 \mathrm{~cm}^{-1}$ were fixed. For all the optimized structures in the library harmonic force fields, polarizability and optical activity tensor derivatives ${ }^{41}$ were obtained at the same B3LYP/6-31+G**/CPCM level.

Spectra Generation. For the 1000 structures from the MD runs, Raman and ROA frequencies and intensities were obtained 


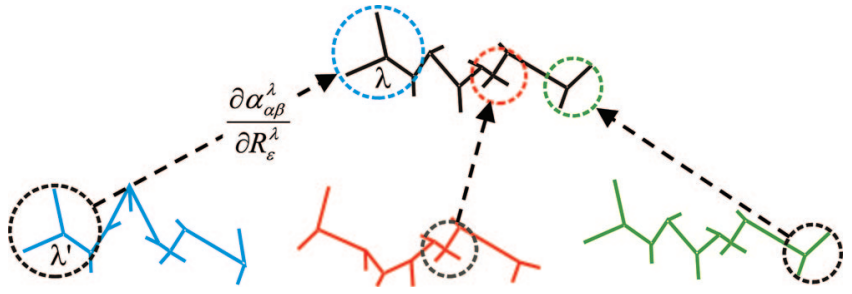

Figure 3. Schematic representation of tensor transfer: For each atom $\lambda$ of a geometry obtained by MD (top, black), the tensor derivatives (e.g., of polarizability $\alpha$ ) were transferred from a library structure (bottom) providing the best local overlap. The force field (second energy derivatives) comprising two atoms was transferred similarly.

by Cartesian coordinate tensor transfer ${ }^{30}$ using the ab initio library of 27 conformers described above. The Cartesian Hessian (second energy derivatives) and electric dipole-electric dipole, electric dipole-magnetic dipole, and electric dipole-electric quadrupole polarizability tensors were transferred atom by atom, according to the local best overlap of the target MD structure with the library geometries. As schematically indicated in Figure 3 , more ab initio structures could be used for each MD geometry, exploring the local conformational similarity of molecular segments. Then the Hessian for each MD geometry was diagonalized and vibrational normal modes thus obtained were combined with polarization tensors to provide the ICP backscattered Raman and ROA intensities. ${ }^{6,41,42}$ Averaged Raman and ROA spectra were generated as plain sums comprising all the MD structures. The spectra were additionally smoothed by use of Lorentzian shapes of $10 \mathrm{~cm}^{-1}$ full width at half-height.

\section{Results and Discussion}

Conformer Distribution. Torsion angles and relative conformer energies of D-gluconic acid anion structures selected in the $a b$ initio library are summarized in Table 1 . We can observe that the canonical angles $\left(60^{\circ},-60^{\circ}\right.$, and $\left.180^{\circ}\right)$ of the $\mathrm{sp}^{3}$ hybridization are significantly distorted (especially $60^{\circ}$ and $-60^{\circ}$ ), clearly because of internal hydrogen-bond formation. The charged $\mathrm{COO}^{-}$group strongly influences conformation of the neighboring hydroxyls up to $\omega_{4}$; for example, stable conformations with $\omega_{2} \sim 0^{\circ}$ only could be found. For $\omega_{5}$ and $\omega_{6}$, all three conformations are possible. Structures 5 and 6 converged to the same geometry.

Relative conformer energies for the normal mode optimized structures $(16-27$, see Table 1) are strongly influenced by the mode constraints and cannot be directly compared to the fully optimized conformers $(1-15)$. Additionally, the ab initio (B3LYP/6-31+G**/CPCM) predictions might not be reliable as the purely electrostatic continuum solvent model does not sufficiently describe the many hydrogen bonds between the solute and the solvent. Note that a single hydrogen bond associated with energy of $\sim 10 \mathrm{kcal} / \mathrm{mol}$ can potentially reverse the conformational ordering. Normally, proper solvent treatment smoothes the conformer energy differences. ${ }^{5}$ Although we did not use $a b$ initio energies in the spectral averaging, they provide useful qualitative feedback on the choice of the conformers and feasibility of the MD conformer distribution. Particularly, we see that various conformers can be realized easily within very small energy changes.

Indeed, the torsion angle distributions obtained by MD (Figure 4 for $\psi_{i}$ and Figure 5 for $\omega_{i}$ ) suggest a large conformational flexibility. MD simulations also appear more realistic than CPCM due to the involvement of explicit water molecules. The Amoeba force field provides similar averaged values and distribution widths as Amber95/99; however, being much slower, the Amoeba simulations could not be run until equilibration and some conformers, especially those including different backbone shapes (Figure 4), are completely missing for this force field. For example, $\psi_{3} \sim 60^{\circ}$ appeared for the longer Amber95 run (trace c), but not for the shorter Amoeba and Amber95 runs (traces a and b, respectively). Therefore, we find the longer Amber95/99 MD simulation more reliable, although we still cannot guarantee that all possible conformers are completely balanced. Surprisingly, small changes in the Amber95 and Amber99 parametrizations resulted in notably different distributions, particularly for the torsion angles in the vicinity of the carboxyl terminus. Qualitatively, the distributions are similar, except for the angle $\psi_{2}$. However, we did not notice particular differences in the resultant spectra stemming from the $\psi_{2}$ rotation.

Equilibration, especially that of the $\mathrm{C}-\mathrm{C}$ backbone angle conformers, requires computational times beyond our current possibilities. This can also be documented in Figure 6 where the time dependencies of $\psi_{1}\left(\mathrm{COO}^{-}\right.$rotation $), \psi_{3}$, and $\omega_{4}$ angles are compared. While the $75 \mathrm{~ns}$ simulation run is quite sufficient for the relatively fast-rotating $\mathrm{COO}^{-}$group, the $\psi_{3}$ backbone rotation appears to be about 10 times slower and the current simulation ensures only partial conformational equilibrium. Nevertheless, the MD model allows for at least qualitative estimation of the molecular conformational flexibility and equilibration of the fastest molecular motions. Indeed, the $\mathrm{OH}$ groups move much more quickly than the backbone, which can be seen from the $\omega_{4}$ dependence in Figure 6, but also from the distributions in Figure 5, providing converged patterns already for the $1 \mathrm{~ns}$ runs.

Both ab initio relative energies (Table 1) and MD angular distributions (Figure 4) suggest that backbone-extended conformations are quite frequent but not dominant in the sample. Such conclusions about the behavior of the $-\mathrm{CHOH}$ - skeleton are also in agreement with a similar MD study performed for the glycerol molecule. ${ }^{22}$ Interestingly, the backbone angles close to the $\mathrm{COO}^{-}$group $\left(\psi_{1-3}\right.$, see Figure 4$)$ appear more rigid than the other two, which is most probably caused by the hydroxyl groups forming an internal hydrogen-bond network, with some participation of the water molecules.

Vibrational Spectra. By default the B3LYP functional was chosen for simulation of the spectral properties. In the past this method, if combined with basis sets containing polarization functions, provided reliable Raman and ROA intensities. ${ }^{13,43}$ Systematic tests ${ }^{42}$ indicate that for this purpose B3LYP results do not significantly differ from those obtained by other advanced hybrid or pure (GGA) DFT methods. For example, the Raman and ROA spectra obtained by the B3LYP and BPW91 functionals plotted in Figure 7 (upper two traces) are quite similar in terms of computed frequencies, relative intensities, and signs. The $6-31+\mathrm{G}^{* *}$ basis and CPCM solvent model were used. A closer look reveals that the ROA intensities vary more than the Raman profiles. As expected, only an approximate match between the simulations and the experiment (lower trace in Figure 7) is obtained for the one-conformer computation.

On the basis of the simulation, however, we could assign most of the observed bands to particular vibrational normal modes, as indicated in Figure 8. The carboxyl $\mathrm{COO}^{-}$group provides very distinctive signals at $1594 \mathrm{~cm}^{-1}$ (locally asymmetric, out-of-phase $\mathrm{C}=\mathrm{O}$ stretch; the peak is broadened by hydrogen bonding), and $881 \mathrm{~cm}^{-1}$ (mostly out-of-plane carbon deviation). The computations suggest that the mode at $881 \mathrm{~cm}^{-1}$ is also strongly coupled with the $\mathrm{C}-\mathrm{C}$ stretching modes. The 

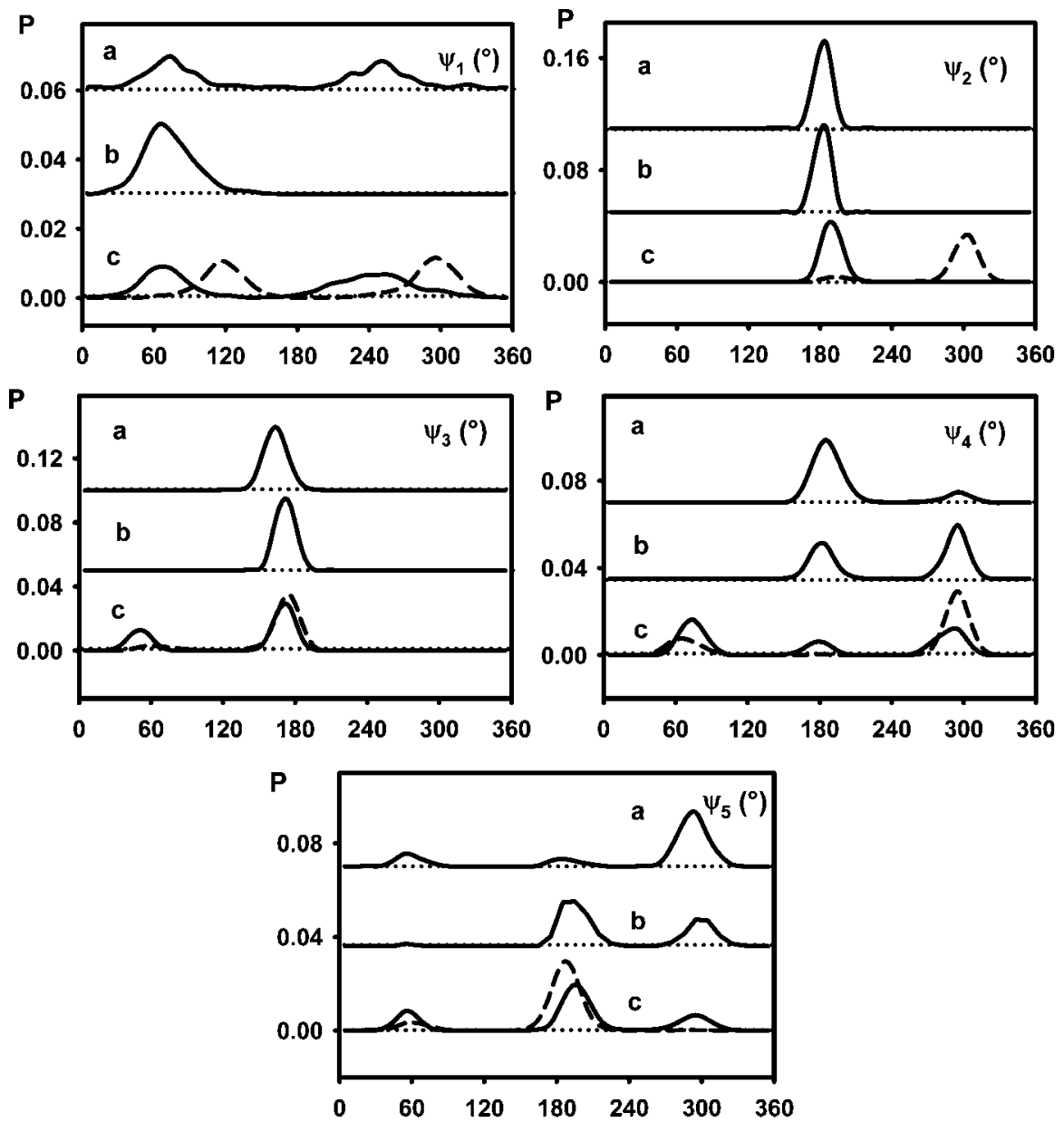

Figure 4. MD probability distributions of the backbone $\mathrm{C}-\mathrm{C}$ torsion angles for the Amoeba force field (a) and for short (1 ns, b) and longer (75 ns, c) runs with the Amber95 force field. For traces c, distributions obtained with Amber99 are added and plotted by the dashed line.

TABLE 1: Torsion Angles in Optimized D-Gluconic Anion Structures Used as the Ab Initio Conformer Library with Corresponding Relative Energies

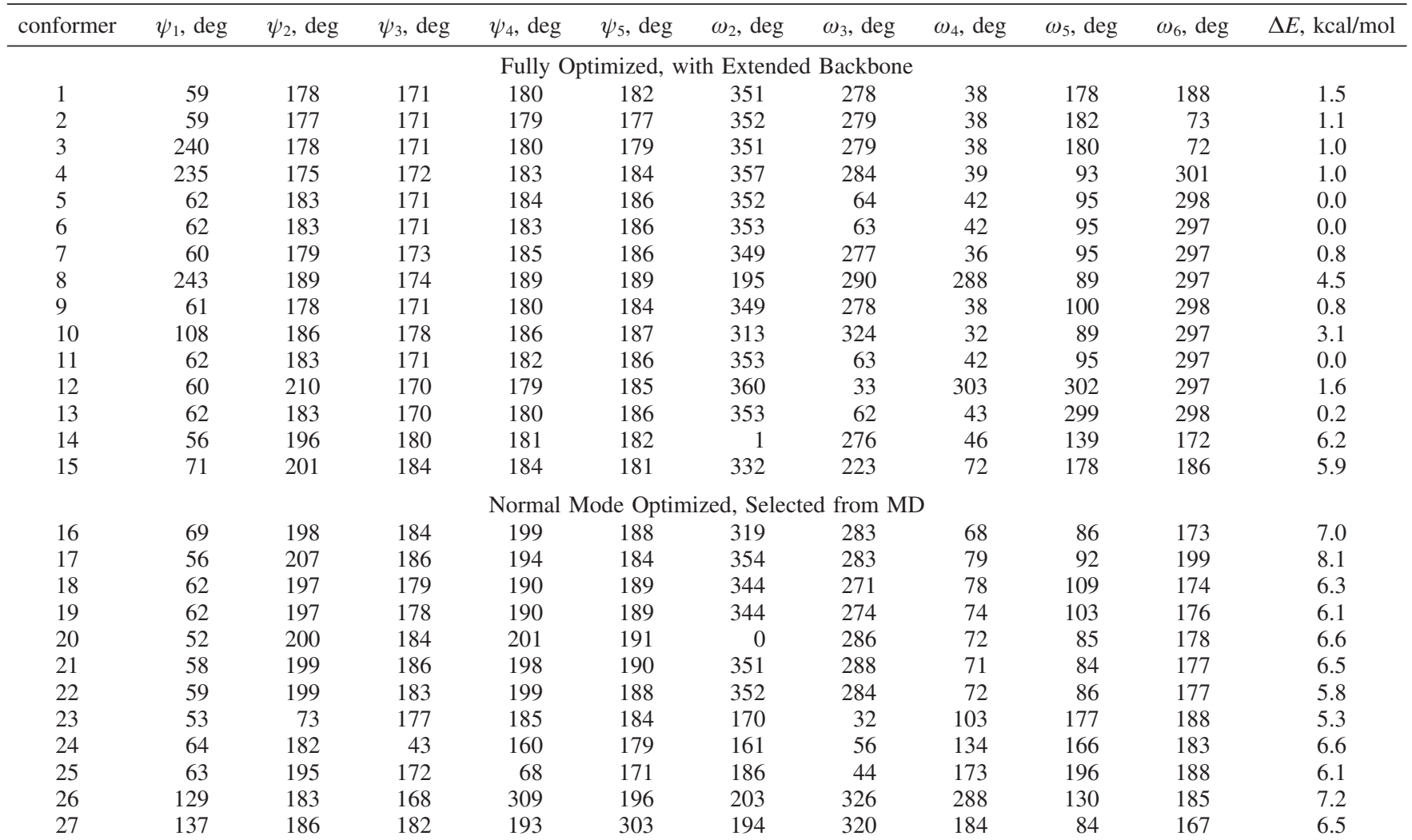



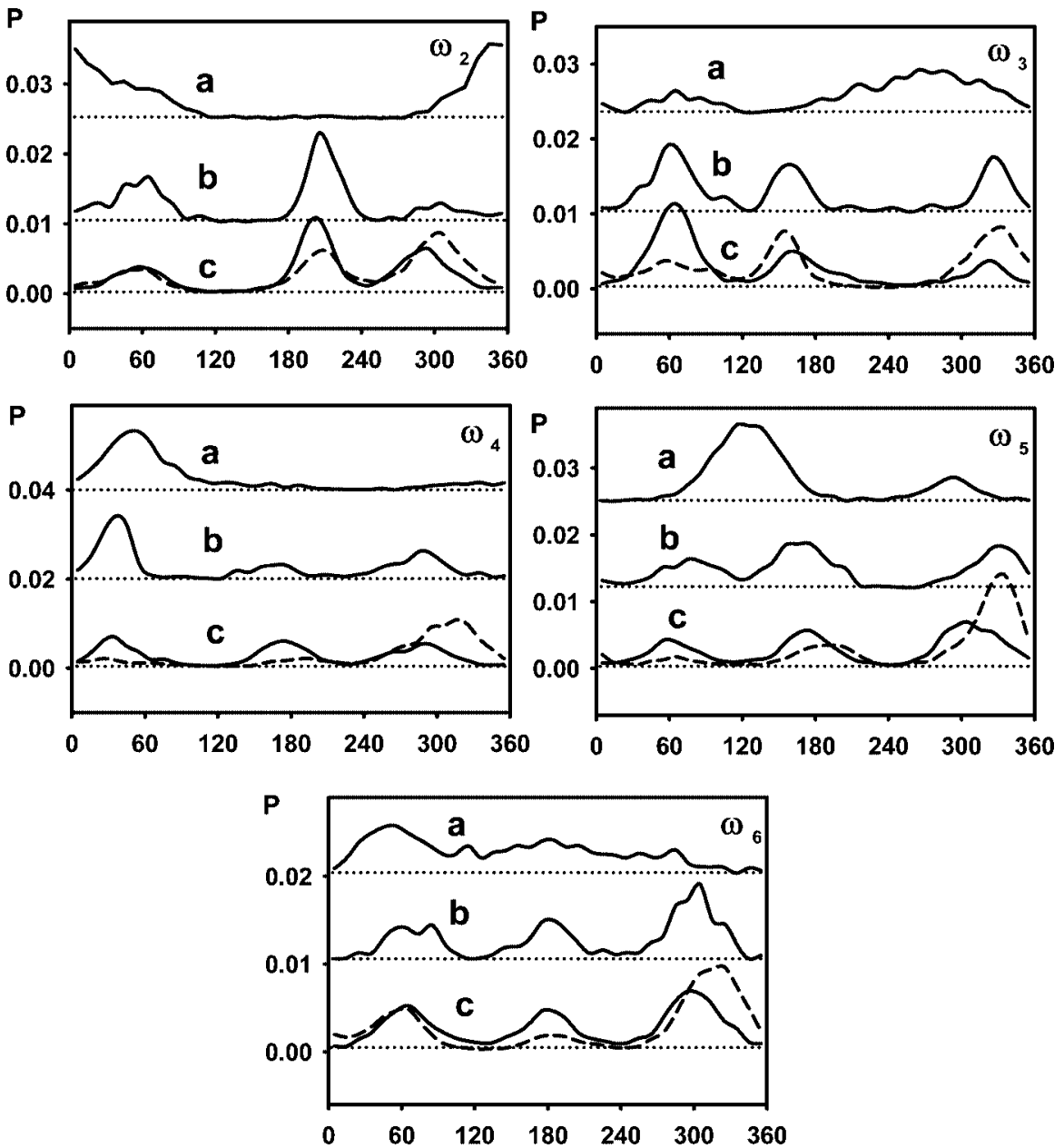

Figure 5. MD distributions of the $\mathrm{C}-\mathrm{OH}$ torsion angles for the Amoeba force field (a) and for short (1 ns, b) and longer (75 ns, c) runs with Amber95 (dashed line, Amber99) force field.

locally symmetric (in-phase) $\mathrm{C}=\mathrm{O}$ stretching mode is hidden in a broad signal of $\mathrm{CH}$ and $\mathrm{OH}$ bending $\left(\sim 1200-1500 \mathrm{~cm}^{-1}\right)$, where only the $\mathrm{CH}_{2}$ scissoring mode $\left(1462 \mathrm{~cm}^{-1}\right)$ can clearly be identified, as it is relatively independent of molecular conformation and not significantly coupled to other vibrations. The $\mathrm{C}-\mathrm{O}$ and $\mathrm{C}-\mathrm{C}$ stretching region $\left(\sim 1020-1140 \mathrm{~cm}^{-1}\right)$ also provides a broad and only partially structured band, but in a narrower frequency range than the $\mathrm{CH} / \mathrm{OH}$ bending. The vibrational modes below $\sim 900 \mathrm{~cm}^{-1}$ become more separated, but the vibrations are mostly delocalized and less specific. The out-of-plane vibrations even occur mixed into the $\mathrm{O}=\mathrm{C}=\mathrm{O}$ and $\mathrm{C}-\mathrm{C}-\mathrm{C}$ bending modes within $\sim 600-700 \mathrm{~cm}^{-1}$; but the Raman signal here is much weaker.

Solvent Effect. The effect of solvent corrections can be documented in Figure 9, where the vacuum (B3LYP/6-31+G**) Raman spectra are compared with those obtained with the CPCM continuum model, a vacuum computation where the solvent molecules were replaced by partial atomic charges $\left(q_{\mathrm{H}}\right.$ $\left.=0.4, q_{\mathrm{O}}=-0.8\right)$, and a cluster containing explicit water molecules. A random MD geometry was chosen for all the models. In the clusters hydrogen-bonded water molecules closer than $3.6 \AA$ were conserved only, and resultant structures were subjected to the constrained normal mode optimization. We can observe two main solvent-induced changes: (1) Many frequencies become significantly shifted, mostly to lower values. For example, the $\mathrm{C}=\mathrm{O}$ out-of-phase band calculated in vacuum at $1703 \mathrm{~cm}^{-1}$ shifts to $\sim 1600 \mathrm{~cm}^{-1}$. Rather exceptionally, the inphase $\mathrm{C}=\mathrm{O}$ stretching shifts from $1355 \mathrm{~cm}^{-1}$ in vacuum up to
$1371 \mathrm{~cm}^{-1}$ in CPCM and even to $\sim 1391 \mathrm{~cm}^{-1}$ for the explicit water cluster. These effects are thus reproduced by both the continuum and cluster solvent models. At the same time, (2) vibrational bands split and the relative intensities are redistributed; this effect is overemphasized in the cluster models (either with the explicit molecules or with the charges), while more modest changes are provided by CPCM, inherently accounting for the solvent position averaging. For example, the gas-phase band around $781 \mathrm{~cm}^{-1}$ (out-of-plane and scissor $\mathrm{COO}^{-}$bending) splits with CPCM to two overlapping bands, which become completely separated in the cluster.

The in-phase $\mathrm{C}=\mathrm{O}$ stretching frequency upshift in solvent is rather counterintuitive and deserves special attention. Normally, the $\mathrm{C}=\mathrm{O}$ bond is weakened by the solvent and the frequency goes down. ${ }^{44,45}$ However, the upshift can be explained by coupling with the $\mathrm{C}-\mathrm{C}$ stretching bond as it is overviewed in Figure 10 for a model molecule. While it is true that the $\mathrm{C}=\mathrm{O}$ bond is significantly weakened, similarly as in neutral carbonyl groups, the $\mathrm{C}-\mathrm{C}$ bond is strengthened in the polar solvent (water), probably partially acquiring double-bond character. Additionally, the $\mathrm{C}-\mathrm{C}$ stretching participates more in the inphase vibration in solvent. In a final effect, the $\mathrm{C}=\mathrm{O}$ weakening is outweighed by coupling with the other vibration and the frequency increases.

Molecular Flexibility. Besides the solvent-induced broadening of spectral lines, the Raman and ROA intensities are strongly influenced by molecular conformation. In Figure 11, average frequency deviations of selected normal modes are plotted for 

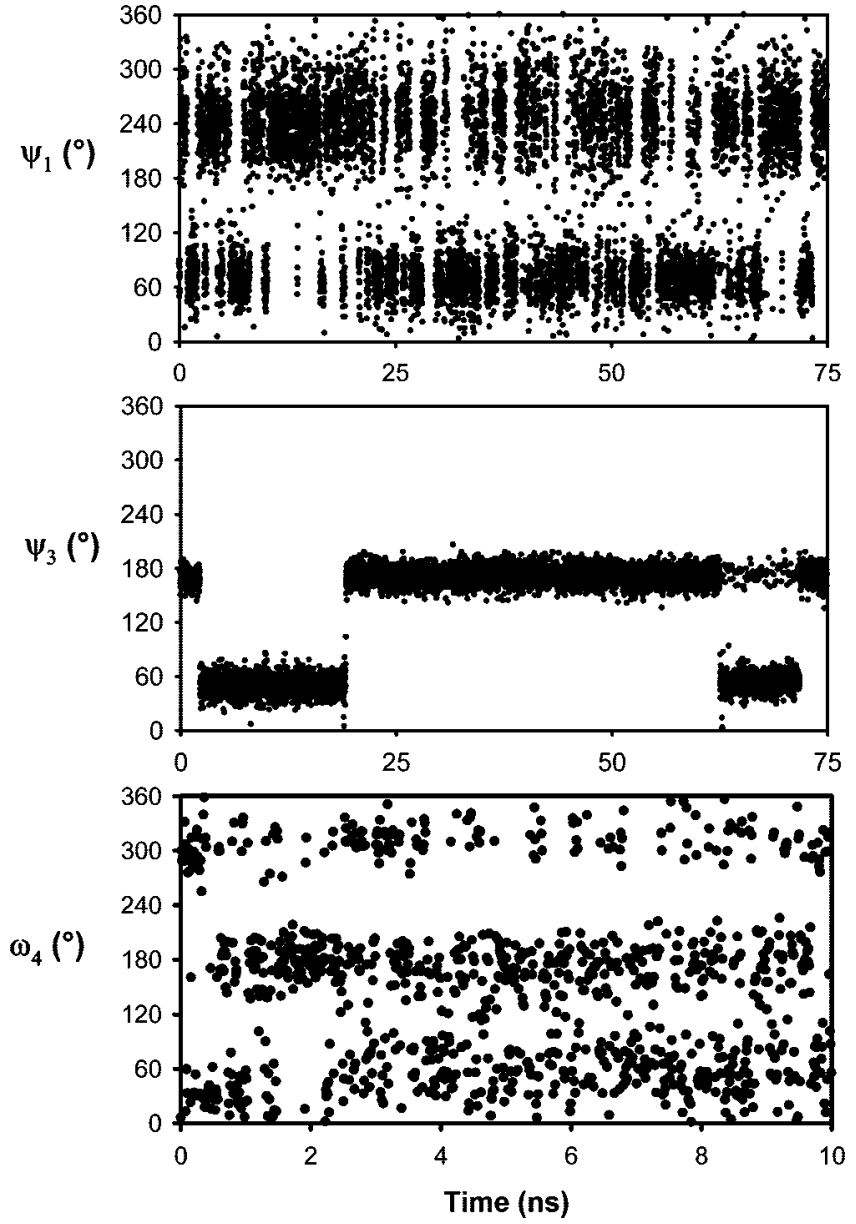

Figure 6. Time development of $\psi_{1}, \psi_{3}$, and $\omega_{4}$ torsion angles during the Amber95 MD simulation. Note the different time scales.
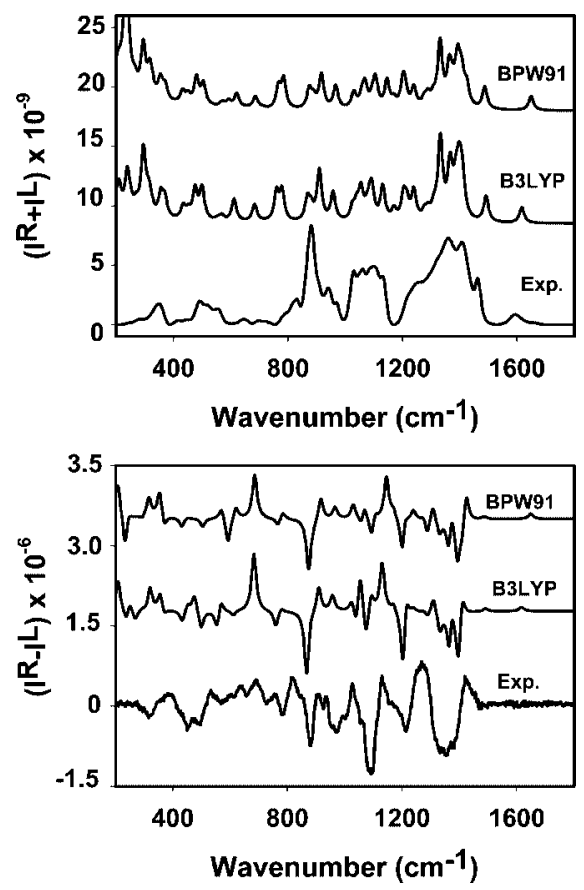

Figure 7. Comparison of Raman (top) and ROA (bottom) spectra calculated at the B3LYP and BPW91 levels (both with 6-31+G** basis and CPCM solvent correction) with experiment. Simulations were performed for one library conformer (11).

the library structures from Table 1 . Individual vibrations are somewhat differently sensitive, but considerable changes can

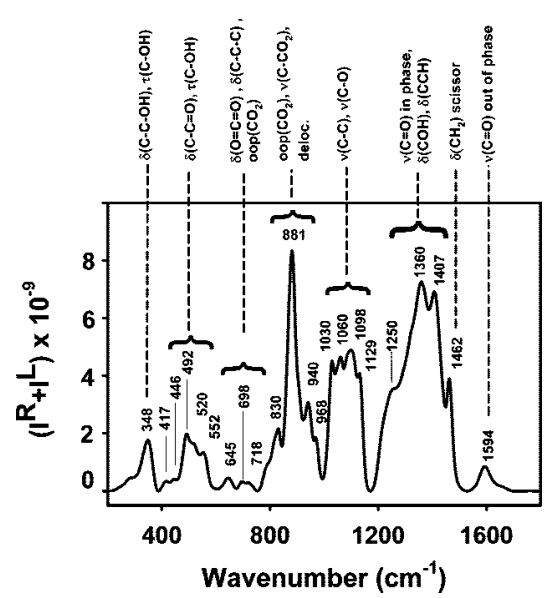

Figure 8. Experimental Raman spectra of gluconic acid anion and typical vibrations most contributing to the intensities as assigned on the basis of B3LYP/6-31+G**/CPCM computations and visualization of the normal mode displacements. Abbreviations: $\delta$, bending; $\tau$, torsion; $v$, stretching; oop, out of plane.

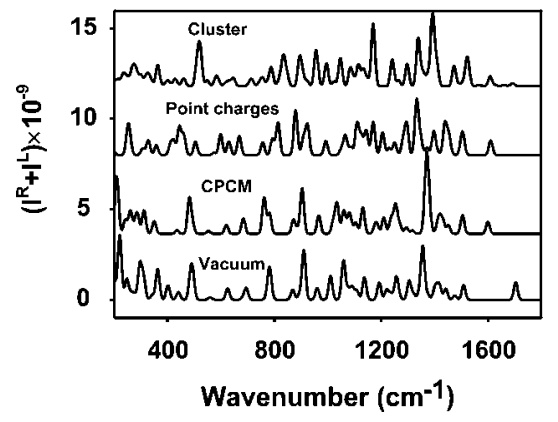

Figure 9. Simulated (B3LYP/6-31+G**) Raman spectra of one D-gluconic anion conformer. Vacuum spectra are compared with those obtained by continuum, point charge, and cluster solvent models.

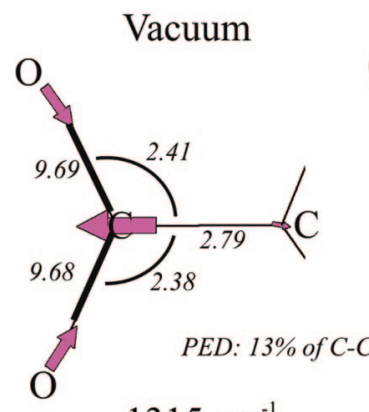

$1315 \mathrm{~cm}^{-1}$

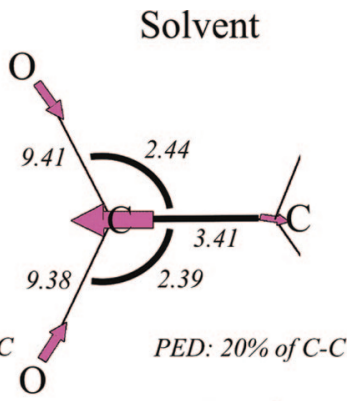

$1356 \mathrm{~cm}^{-1}$
Figure 10. Effect of solvent on in-phase $\mathrm{C}=\mathrm{O}$ stretching, as calculated for the $\mathrm{CH}_{3}-\mathrm{COO}^{-}$model molecule at the BPW91/6-31G**(CPCM) level: From the normal mode displacement (magenta arrows) and potential energy distribution (PED), we see an increased participation of the $\mathrm{C}-\mathrm{C}$ stretching in this mode; harmonic bond $\mathrm{C}-\mathrm{C}$ bond and $\mathrm{C}-\mathrm{C}=\mathrm{O}$ angle strengths are increased, while $\mathrm{C}=\mathrm{O}$ bond strengths decrease, and as a result the solvent frequency is higher. Relative bond and angle strengths are emphasized by the different line widths; the calculated harmonic strengths constant (in a.u.) are listed in italic type.

be observed across the entire region of the spectrum. Visualization of the normal modes (Figure 10, top) suggests that the frequency dispersion can rather be correlated to the vibration type (vibrations 4, 6, and 8 involving nonpolar $\mathrm{CH}_{2}$ and $\mathrm{CH}$ groups are dispersed less) than to the locality and coupling pattern. But the correlation is very weak and unconvincing, similarly as for the intensity dispersion (not shown). Therefore, only complete conformer averaging can provide realistic spectral 


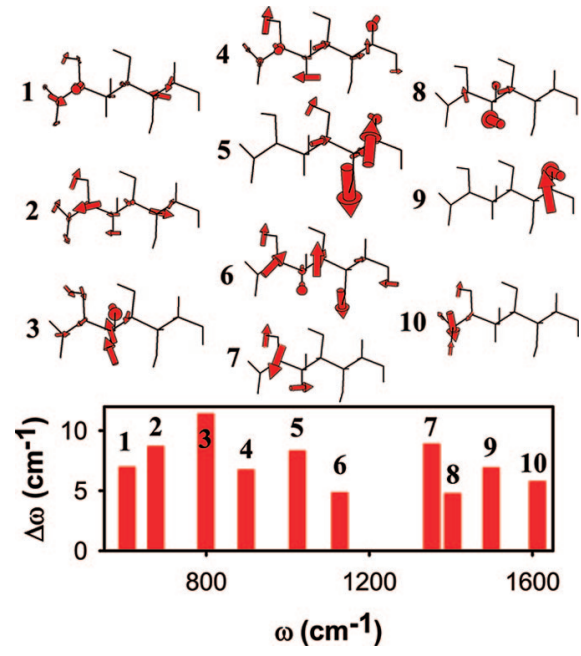

Figure 11. Average absolute frequency deviations for 10 randomly selected vibrations, computed from the conformers listed in Table 1. Corresponding normal mode displacements (for conformer 11) are indicated.
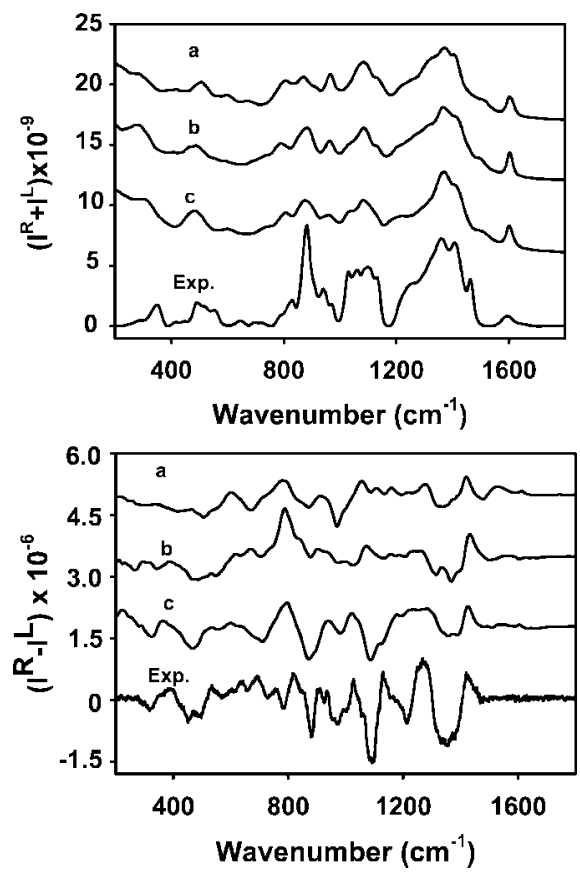

Figure 12. Simulated (B3LYP/6-31+G**/CPCM fragment library) and experimental Raman (top) and ROA (bottom) spectra of D-gluconic acid anion. Simulations were based on Amoeba 1 ns (traces a) and Amber 951 (b) and 75 ns (c) MD run averages.

patterns. Indeed, the averaged spectra in Figure 12 provide a very reasonable match to the experiment. Interestingly, all the Amoeba and short (1 ns) and long (75 ns) Amber95 runs (traces $\mathrm{a}, \mathrm{b}$, and $\mathrm{c}$ in Figure 12, respectively) give similar Raman patterns. The shape of the $\mathrm{OH}$ and $\mathrm{CH}$ bending region (1200-1500 $\mathrm{cm}^{-1}$ ) corresponds well to the experiment, as do the simulations within $\sim 200-800 \mathrm{~cm}^{-1}$. The experimental peak at $882 \mathrm{~cm}^{-1}$ is sharper and the plateau at $1028-1132 \mathrm{~cm}^{-1}$ is flatter than simulated. Around $700 \mathrm{~cm}^{-1}$ the spectrum obtained with the Amoeba force field is more structured, in favor to the agreement with the experiment, which suggests that inclusion of polarization effects might be important for precise modeling.

ROA spectra are much more sensitive to geometry and MD force field selection than Raman intensities. Within $~ 1250-1600$ $\mathrm{cm}^{-1}$ the " +-+ " ROA sign pattern is approximately matched by all the models, but within the entire region the longest Amber95 $75 \mathrm{~ns}$ simulation (trace $\mathrm{c}$ in Figure 11) clearly agrees with the experiment more than the shorter Amoeba and Amber95 $1 \mathrm{~ns}$ runs (traces a and b). Although the accuracy of the simulation is limited, we can thus demonstrate that the ROA technique is much more sensitive to the molecular structure and dynamics than the unpolarized Raman spectroscopy. The better agreement of the longer simulation runs also confirms the MD finding that significant population of the molecules adopts backbone-bent conformations, in addition to the extended ones. Averaging of many conformations is thus vital to correct modeling. Unlike for the conventional continuum solvent models, solvent positions have to be averaged in the clusters as well. The carboxyl group provides a good example of various averaging effects, as the ROA signal of the $\mathrm{C}=\mathrm{O}$ asymmetric stretching band $\left(\sim 1600 \mathrm{~cm}^{-1}\right)$ averages to zero, while a strong structured signal remains in the symmetric stretching region due to coupling with $\mathrm{OH}$ bending.

\section{Conclusions}

Within the combined MD/ab initio model, a large number of gluconate spectra could be generated for geometries produced by molecular dynamics, using spectral parameters calculated quantum mechanically for a limited library of conformers. The Cartesian coordinate-based method proved as an effective tool for tensor transfer. The simulated spectra reproduce most of the features observed in the experimental Raman and ROA intensities. Remaining errors can be attributed to inaccuracy of MD force field, limited ab initio conformer library, limitations of the harmonic and density functional approximations, and the solvent model. Both MD and spectral-simulation results confirm that the $\mathrm{OH}$ as well as the skeletal bonds exhibit a semifree rotation, partially limited by the influence of the charged $\mathrm{COO}^{-}$ group, and that a large ROA signal is possible for most vibrations even after conformational averaging. The increased sensitivity of ROA to molecular geometry is thus conserved, and if combined with simulation the technique can conveniently be used for structural studies of flexible saccharide derivatives in aqueous solutions.

Acknowledgment. This work was supported by the Danish Center for Scientific Computing, the Czech Science Foundation (Grants 203/06/0420 and 202/07/0732), and the Grant Agency of the Academy of Sciences (A4005507020).

\section{References and Notes}

(1) Barron, L. D.; Buckingham, A. D. Mol. Phys. 1971, 20, 1111.

(2) Barron, L. D.; Bogaard, M. P.; Buckingham, A. D. J. Am. Chem. Soc. 1973, 95, 603 .

(3) Barron, L. D.; Zhu, F.; Hecht, L. Vib. Spectrosc. 2006, 42, 15.

(4) Nafie, L. A.; Freedman, T. B. Vibrational optical activity theory. In Circular Dichroism. Principles and Applications, 2nd ed.; Berova, N., Nakanishi, K., Woody, R. W., Eds.; Wiley-VCH: New York, 2000.

(5) Buděšínský, M.; Šebestík, J.; Bednárová, L.; Baumruk, V.; Šafařík, M.; Bouř, P. J. Org. Chem. 2008, 73, 1481.

(6) Polavarapu, P. L. Vibrational spectra: principles and applications with emphasis on optical activity; Elsevier: Amsterdam, 1998; Vol. 85.

(7) Blanch, E. W.; Hecht, L.; Symme, C. D.; Volpetti, V.; Lomonossoff, G. P.; Barron, L. D. J. Gen. Virol. 2002, 83, 2593.

(8) Costante, J.; Hecht, L.; Polavarapu, P. L.; Collet, A.; Barron, L. D. Angew. Chem., Int. Ed. 1997, 36, 885.

(9) Haesler, J.; Schindelholz, I.; Riguet, E.; Bochet, C. G.; Hug, W. Nature 2007, 446, 526.

(10) Buděšínský, M.; Daněček, P.; Bednárová, L.; Kapitán, J.; Baumruk, V.; Bouř, P. J. Phys. Chem. 2008, 112, 8633.

(11) Bell, A. F.; Hecht, L.; Barron, L. D. Chem.-Eur. J. 1997, 3, 1292.

(12) Barron, L. D.; Gargaro, A. R.; Hecht, L.; Polavarapu, P. L.; Sugeta, H. Spectrochim. Acta, Part A 1992, 48, 1051. 
(13) Kapitán, J.; Baumruk, V.; Kopecký, V., Jr.; Bouř, P. J. Phys. Chem. A 2006, 110, 4689.

(14) Zhang, Z.; Bottenus, B.; Clark, S. B.; Tian, G.; Zanonato, P. L.; Rao, L. J. Alloys Compd. 2007, 444-445, 470.

(15) Gyurscik, B.; Nagy, L. Coord. Chem. Rev. 2000, 203, 81.

(16) Chelli, R.; Procacci, P.; Cardini, G.; Della Valle, R. G.; Califano, S. Phys. Chem. Chem. Phys. 1999, 1, 871.

(17) Teppen, B. J.; Cao, M.; Frey, R. F.; Van Alsenoy, C.; Miller, D. M.; Schäfer, L. J. Mol. Struct. (THEOCHEM) 1994, 314, 169.

(18) van den Enden, L.; Van Alsenoy, C.; Scarsdale, J. N.; Schäfer, L. J. Mol. Struct. (THEOCHEM) 1983, 104, 471.

(19) Van Alsenoy, C.; Klimkowski, V. J.; Ewbank, J. D.; Schäfer, L. J. Mol. Struct. (THEOCHEM) 1985, 121, 153.

(20) Chelli, R.; Gervasio, F. L.; Gellini, C.; Procacci, P.; Cardini, G.; Schettino, V. J. Phys. Chem. A 2000, 104, 5351.

(21) Chelli, R.; Gervasio, F. L.; Gellini, C.; Procacci, P.; Cardini, G.; Schettino, V. J. Phys. Chem. A 2000, 104, 11220.

(22) Yongye, A. B.; Foley, B. L.; Woods, R. J. J. Phys. Chem. A 2008, $112,2634$.

(23) Amos, R. D. Chem. Phys. Lett. 1982, 87, 23.

(24) Helgaker, T.; Ruud, K.; Bak, K. L.; Joergensen, P.; Olsen, J. Faraday Discuss. 1994, 99, 165.

(25) Ruud, K.; Helgaker, T.; Bouř, P. J. Phys. Chem. A 2002, 106, 7448.

(26) Bouř, P. J. Comput. Chem. 2001, 22, 426.

(27) Frisch, M. J.; Trucks, G. W.; Schlegel, H. B.; Scuseria, G. E.; Robb, M. A.; Cheeseman, J. R.; Montgomery, J. A., Jr.; Vreven, T.; Kudin, K. N.; Burant, J. C.; Millam, J. M.; Iyengar, S. S.; Tomasi, J.; Barone, V.; Mennucci, B.; Cossi, M.; Scalmani, G.; Rega, N.; Petersson, G. A.; Nakatsuji, H.; Hada, M.; Ehara, M.; Toyota, K.; Fukuda, R.; Hasegawa, J.; Ishida, M.; Nakajima, T.; Honda, Y.; Kitao, O.; Nakai, H.; Klene, M.; Li, X.; Knox, J. E.; Hratchian, H. P.; Cross, J. B.; Bakken, V.; Adamo, C.; Jaramillo, J.; Gomperts, R.; Stratmann, R. E.; Yazyev, O.; Austin, A. J.; Cammi, R.; Pomelli, C.; Ochterski, J. W.; Ayala, P. Y.; Morokuma, K.; Voth, G. A.; Salvador, P.; Dannenberg, J. J.; Zakrzewski, V. G.; Dapprich, S.; Daniels, A. D.; Strain, M. C.; Farkas, O.; Malick, D. K.; Rabuck, A. D.; Raghavachari, K.; Foresman, J. B.; Ortiz, J. V.; Cui, Q.; Baboul, A. G.; Clifford, S.; Cioslowski, J.; Stefanov, B. B.; Liu, G.; Liashenko, A.; Piskorz, P.; Komaromi, I.; Martin, R. L.; Fox, D. J.; Keith, T.; Al-Laham, M. A.; Peng, C. Y.; Nanayakkara, A.; Challacombe, M.; Gill, P. M. W.; Johnson, B.; Chen, W.; Wong, M. W.; Gonzalez, C.; Pople, J. A. Gaussian 03, Revision C.02; Gaussian, Inc.: Wallingford CT, 2004.
(28) Angeli, C.; Bak, K. L.; Bakken, V.; Christiansen, O.; Cimiraglia, R.; Coriani, S.; Dahle, P.; Dalskov, E. K.; Enevoldsen, T.; Fernandez, B.; Haettig, C.; Hald K.; Halkier, A.; Heiberg, H.; Helgaker, T.; Hettema, H.; Jensen, H. J. A.; Jonsson, D.; Joergensen, P.; Kirpekar, S.; Klopper, W.; Kobayashi, R.; Koch, H.; Lutnaes, O. B.; Mikkelsen, K. V.; Norman, P.; Olsen, J.; Packer, M. J.; Pedersen, T. B.; Rinkevicius, Z.; Rudberg, E.; Ruden, T. A.; Ruud, K.; Salek, P.; Sanchez de Meras, A.; Saue, T.; Sauer, S. P. A.; Schimmelpfennig, B.; Sylvester-Hvid, K. O.; Taylor, P. R.; Vahtras, O.; Wilson, D. J.; Agren, H. Dalton, a molecular electronic structure program; Release 2.0 ed.; University of Oslo: Oslo, Norway, 2005.

(29) Liegeois, V.; Ruud, K.; Champagne, B. J. Chem. Phys. 2007, 127, 204105.

(30) Bouř, P.; Sopková, J.; Bednárová, L.; Maloň, P.; Keiderling, T. A. J. Comput. Chem. 1997, 18, 646.

(31) Bouř, P.; Baumruk, V.; Hanzlíková, J. Collect. Czech. Chem. Commun. 1997, 62, 1384.

(32) Kapitán, J.; Baumruk, V.; Gut, V.; Hlaváček, J.; Dlouhá, H.; Urbanová, M.; Wunsch, E.; Maloň, P. Collect. Czech. Chem. Commun. 2005, $70,403$.

(33) Ponder, J. W. Tinker, Software Tools for Molecular Design; 3.8 ed.; Washington University School of Medicine: St. Louis, MO, 2000.

(34) Cornell, W. D.; Cieplak, P.; Bayly, C. I.; Gould, I. R.; Merz, K. M.; Ferguson, D. M.; Spellmeyer, D. C.; Fox, T.; Caldwell, J. W.; Kollman, P. A. J. Am. Chem. Soc. 1995, 117, 5179.

(35) Wang, J.; Cieplak, P.; Kollman, P. A. J. Comput. Chem. 2000, 21, 1049.

(36) Ren, P.; Ponder, W. J. Phys. Chem. B 2003, 107, 5933.

(37) Jorgensen, W. L.; Chandrasekhar, J.; Madura, J. D. J. Chem. Phys.

1983, 79, 926.

(38) Becke, A. D. J. Chem. Phys. 1993, 98, 5648.

(39) Bouř, P.; Keiderling, T. A. J. Chem. Phys. 2002, 117, 4126.

(40) Bouř, P. Collect. Czech. Chem. Commun. 2005, 70, 1315.

(41) Barron, L. D. Molecular Light Scattering and Optical Activity; Cambridge University Press: Cambridge, U.K., 2004.

(42) Daněček, P.; Bouř, P. J. Chem. Phys. 2007, 126, 224513.

(43) Kapitán, J.; Baumruk, V.; Kopecký, V., Jr.; Pohl, R.; Bouř, P. J. Am. Chem. Soc. 2006, 128, 13451.

(44) Lee, H.; Kim, S. S.; Choi, J. H.; Cho, M. J. Phys. Chem. B 2005, $109,5331$.

(45) Bouř, P.; Michalík, D.; Kapitán, J. J. Chem. Phys. 2005, 122, 144501 .

JP809210N 